\title{
CD62L is not a reliable biomarker for predicting PML risk in natalizumab-treated R-MS patients OPEN
}

Linda A. Lieberman, PhD

Wanyong Zeng, MD

Carol Singh, BS

Wenting Wang, PhD

Kevin L. Otipoby, PhD

Christine Loh, PhD

Tatiana Plavina, $\mathrm{PhD}$

Leonid Gorelik, PhD

Richard M. Ransohoff,

MD

Ellen Cahir-McFarland, $\mathrm{PhD}$

Correspondence to

Dr. Cahir-McFarland:

Ellen.Cahir-McFarland@biogen.com

Supplemental data at Neurology.org

\section{ABSTRACT}

Objective: To assess if the percentage of $\mathrm{CD} 3{ }^{+} \mathrm{CD} 4{ }^{+} \mathrm{CD} 62 \mathrm{~L}^{+}$cells in cryopreserved peripheral blood mononuclear cells (PBMCs) (here termed \%CD62L) can predict risk of developing progressive multifocal leukoencephalopathy (PML) and better inform the physician for benefit-risk assessment of natalizumab treatment decisions in a global setting.

Methods: Cryopreserved PBMCs from 21 natalizumab-treated patients who developed PML and 104 matched natalizumab-treated patients with multiple sclerosis (MS) without PML collected as a part of Biogen clinical trials were retrospectively examined for CD3, CD4, CCR7, CD45RA, and CD62L by flow cytometry.

Results: In this cohort, \%CD62L in natalizumab-treated patients did not predict PML risk. Natalizumab-treated patients with MS without PML showed highly variable \%CD62L upon serial sampling. In the STRATA study, the distribution of \%CD62L in samples collected more than 6 months before a PML diagnosis, at diagnosis, and in natalizumab-treated patients without PML overlapped. No statistical threshold for risk could be determined. In addition, we demonstrated that lymphocyte viability strongly affects \%CD62L, supporting previous reports that \%CD62L is inherently unstable following cryopreservation and is sensitive to sample collection.

Conclusion: Data from this well-controlled cohort of natalizumab-treated patients indicate that \%CD62L is not a biomarker of PML risk. Neurology ${ }^{\circledR} 2016 ; 86: 375-381$

\section{GLOSSARY}

CV = coefficient of variation; JCV = JC virus; MRSA = methicillin-resistant Staphylococcus aureus; MS = multiple sclerosis; PBMC = peripheral blood mononuclear cell; PBS = phosphate-buffered saline; PML = progressive multifocal leukoencephalopathy; $\mathbf{R}-\mathbf{M S}=$ relapsing forms of multiple sclerosis.

Natalizumab is a highly efficacious treatment for relapsing forms of multiple sclerosis (R-MS). ${ }^{1}$ Patients who are seropositive for the anti-JC virus (JCV) antibody and exposed to multiple doses of natalizumab (more than 2 years of therapy) are at higher risk for developing progressive multifocal leukoencephalopathy (PML) and this risk is further increased if patients received immunosuppressive therapy before starting natalizumab. ${ }^{2}$ While the current risk algorithm identifies patients at risk for PML, it would be advantageous to discover factors that reliably predict risk with greater specificity. Expression of L-selectin (CD62L) on $\mathrm{CD} 3{ }^{+} \mathrm{CD} 4^{+} \mathrm{T}$ cells in cryopreserved peripheral blood mononuclear cells (PBMCs) has been proposed as a biomarker for identifying patients at risk for developing PML after long-term treatment with natalizumab. CD62L is a lymph node homing determinant on naive and central memory lymphocytes. It has been reported that patients who go on to develop PML have a drop in their \%CD62L at least 4 months and often 2 years prior to diagnosis. ${ }^{3}$

To determine if \%CD62L can be employed to predict PML risk in a well-controlled clinical setting, we took the following approach. First, the assay was modified to enable reproducible, time-insensitive performance in a multicenter setting as would be required for its use in clinical

From Discovery Research, Biogen, Cambridge, MA.

Go to Neurology.org for full disclosures. Funding information and disclosures deemed relevant by the authors, if any, are provided at the end of the article. The Article Processing Charge was paid by Biogen.

This is an open access article distributed under the terms of the Creative Commons Attribution-NonCommercial-NoDerivatives License 4.0 (CC BY-NC-ND), which permits downloading and sharing the work provided it is properly cited. The work cannot be changed in any way or used commercially. 
practice. Each modification was directly shown not to affect assay results (table e-1 on the Neurology ${ }^{\circledR}$ Web site at Neurology.org), in comparison with the previously reported assay. Next, using this assay, we retrospectively evaluated \%CD62L on cryopreserved PBMCs of patients with R-MS taking natalizumab, including those who later developed PML. We did not find a significant difference in \% CD62L in patients with R-MS on natalizumab who did not develop PML as compared to those who developed PML. We also confirmed a positive correlation between lymphocyte viability and \%CD62L expression, highlighting the technique-driven variability of the assay. We conclude that \%CD62L is not a reliable biomarker for determining an individual's risk for PML.

METHODS Natalizumab patient samples. PML, pre-PML (samples collected at least 6 months prior to PML diagnosis), and matched natalizumab-treated non-PML PBMC samples were selected from multiple sclerosis (MS) natalizumab clinical trials and observational studies including STRATA, ${ }^{4}$ STRATIFY-2, and Genetics. The non-PML cases were matched by sex, age, country/region, prior immunosuppressive treatment, and natalizumab exposure. All participants in the present cohort were anti-JCV antibody-positive. The STRATA cohort consisted of 17 pre-PML samples (from 9 patients), 9 PML samples (from 8 patients), and 55 control samples. All were collected outside the United States. The STRATIFY-2 and Genetics samples were collected within the United States. The Genetics study only collected PML samples that were matched to controls in the STRATIFY-2 cohort. The Genetics cohort contained 5 patients with PML (6 samples), whereas the STRATIFY-2 cohort provided 6 patients with PML and 49 natalizumab non-PML cases, matched to 11 patients with PML (5 from Genetics, 6 from STRATIFY-2). The Genetics and STRATIFY-2 patients all participated in the TOUCH registry for US natalizumab patients. Longitudinal samples were selected from PML cases and non-PML natalizumab-treated participants who had PBMCs collected at intervals of at least 6 months. Patient demographics are outlined in table 1 .

Other patient samples. Thirty-four frozen PBMC samples were purchased from Conversant Bio (Huntsville, AL) to test the effects of other medical conditions on the \% CD62L determination. Twenty-one matched healthy donor samples were collected. Eight samples were collected from hospitalized patients who had at least 24 hours bedrest (5 surgery patients). Five samples were collected from methicillin-resistant Staphylococcus aureus (MRSA)-positive patients who had a fever above $38^{\circ} \mathrm{C}$.

Influenza vaccination PBMC samples and corresponding healthy donors were collected and cryopreserved at Biogen (Cambridge, MA).

PBMC cryopreservation protocol. PBMCs were collected in heparinized tubes, shipped at room temperature to contract research organizations (Covance, Princeton, NJ [STRATIFY/ Genetics], or LabCorp, Burlington, NC [STRATA]), and processed within 24-30 hours. PBMCs were isolated by FicollHypaque method, washed and stored in 10\%-20\% dimethyl sulfoxide at $5-10 \times 10^{6} \mathrm{PBMCs} / \mathrm{mL}$. Cells were stored in a Mr. Frosty (Nalgene, Rochester, NY) for 24 hours and transferred to $-150^{\circ} \mathrm{C}$ until shipment. Shipments to Biogen were made on liquid nitrogen.

Antibodies for flow cytometry. Antibodies against CD4 (PE/ Cy7 anti-human CD4 antibody, clone OKT4), CD62L (APC anti-human CD62L antibody, clone DREG-56), CD8 (APC/ Cy7 anti-human CD8 antibody, clone SK1), CCR7 (Brilliant Violet 510 anti-human CD197 antibody, clone G043H7), and CD45RA (Brilliant Violet 785 anti-human CD45RA antibody, clone HI100) were purchased from BioLegend (San Diego, CA). The antibody against CD3 (BUV395 anti-human CD3 antibody, clone UCHT1) was purchased from BD Biosciences (Franklin Lakes, NJ). Each antibody was titrated for optimal staining.

Flow cytometry and data analysis. The frozen PBMCs were thawed in a $37^{\circ} \mathrm{C}$ water bath and transferred into $10 \mathrm{~mL}$ of cold RPMI with 50 units/mL of Benzonase (E1014; Sigma-Aldrich, St. Louis, MO). Pelleted PBMCs were resuspended in $10 \mathrm{~mL}$ of FACS staining buffer $(1 \times$ phosphate-buffered saline $[\mathrm{PBS}]$ with

\section{Table 1 Patient demographics}

\begin{tabular}{|c|c|c|c|c|c|c|c|c|c|c|c|}
\hline & \multicolumn{3}{|l|}{ All samples } & \multicolumn{5}{|l|}{ STRATA } & \multicolumn{3}{|l|}{ Non-STRATA } \\
\hline No. of samples & 104 & 17 & 21 & 55 & 17 & & 9 & & 49 & 0 & 12 \\
\hline \multicolumn{12}{|l|}{ Age, y } \\
\hline \multicolumn{12}{|l|}{ Sex } \\
\hline$\%$ Female & 77.9 & 66.7 & 84.2 & 78.2 & 66.7 & & 75 & & 77.6 & NA & 90.1 \\
\hline \multicolumn{12}{|c|}{ No. of NTZ doses } \\
\hline Mean $\pm S D$ & $63 \pm 17.13$ & $52 \pm 5.57$ & $64 \pm 13.89$ & $50 \pm 8.41$ & $52 \pm 5.57$ & & $70 \pm 1$ & 15.74 & $77 \pm 13.25$ & NA & $59 \pm 10.59$ \\
\hline
\end{tabular}

Abbreviations: $\mathrm{NA}=$ not available; NTZ = natalizumab; $\mathrm{PML}=$ progressive multifocal leukoencephalopathy.

${ }^{a}$ We do not have at diagnosis samples for 2 of these patients. 
$0.1 \% \mathrm{NaN} 3,2 \%$ fetal bovine serum) and cells were counted Cells were centrifuged and then resuspended in FACS staining buffer at a concentration of $2 \times 10^{7} \mathrm{PBMC} / \mathrm{mL}$. Fifty microliters of the cell suspension was added to each well (U-bottom, 96-well plate) and $50 \mu \mathrm{L}$ of appropriately titrated antibody cocktail was added to the cells, resulting in a final staining volume of $100 \mu \mathrm{L}$. Samples were incubated for 30 minutes in the dark at $4^{\circ} \mathrm{C}$. After 3 washes with $1 \times \mathrm{PBS}$, the cells were fixed with BD Phosflow at $4^{\circ} \mathrm{C}$ in the dark for 20 minutes. Cells were then spun down, fix buffer was discarded, and cells were resuspended in $250 \mu \mathrm{L}$ of $1 \times \mathrm{PBS} /$ well. The samples were stored in the dark at $4^{\circ} \mathrm{C}$ for 24 hours then collected on the LSR II flow cytometer (Becton Dickinson, Franklin Lakes, NJ). Data were analyzed with flow cytometry data analysis software FlowJo (Treestar, Ashland, OR). The gating strategy used in these flow cytometric analyses can be found in figure e- 1 . The percentage of live lymphocytes was determined by the fraction of high forward scatter, low side scatter cells of total lymphocyte population (figure e-1). Low forward scatter lymphocytes were confirmed to be annexinpositive and CD62L-negative in comparable samples, whereas high forward scatter lymphocytes were predominantly annexinnegative and CD62L-positive (figure e-2).

Standard protocol approvals, registrations, and patient consents. All investigators for the studies listed obtained approval from their local institutional review board, independent ethics committee, or research ethics board. The studies were performed in accordance with the principles outlined in the Declaration of Helsinki. Written informed consent was obtained from each patient in all studies.
Statistical analysis. An unpaired Student $t$ test was performed for comparison between 2 groups of patients. For repeated measures from the same control natalizumab-treated patients without PML, a Wilcoxon signed-rank test was performed. A Spearman correlation was performed to assess the relationship between lymphocyte viability and \%CD62L. All analysis was conducted with Prism version 6 (Graphpad, La Jolla, CA).

RESULTS \%CD62L is variable on control $\mathrm{CD}^{+}$ T cells. In order to assess the stability of $\%$ CD62L on $\mathrm{CD}^{+} \mathrm{CD}^{+} \mathrm{T}$ cells, we determined $\% \mathrm{CD} 62 \mathrm{~L}$ in a subset of natalizumab-treated patients with MS without PML at 2 time points at least 6 months apart. Among both the STRATA and STRATIFY-2 participants, there was a large range in \%CD62L (STRATA, 0.31-67; STRATIFY-2, 3.74-68.4) at each time point (figure 1A). In the STRATA cohort, the median \%CD62L decreased significantly from time point $1-2$ : 27.5 to $11.3(p<0.0001)$, whereas the $\%$ CD62L values in the STRATIFY-2 cohort did not vary greatly between time points $(p=0.74$; median $\%$ CD62L point $1=20.9$; point $2=19.4$ ).

CD62L is coexpressed with chemokine receptor CCR7 on T cells constituting a lymph node homing signature. To better understand the variability in the $\%$ CD62L measured repeatedly in the same subject in

Figure $1 \% \mathrm{CD} 62 \mathrm{~L}$ is variable in patients taking natalizumab

\section{STRATA}
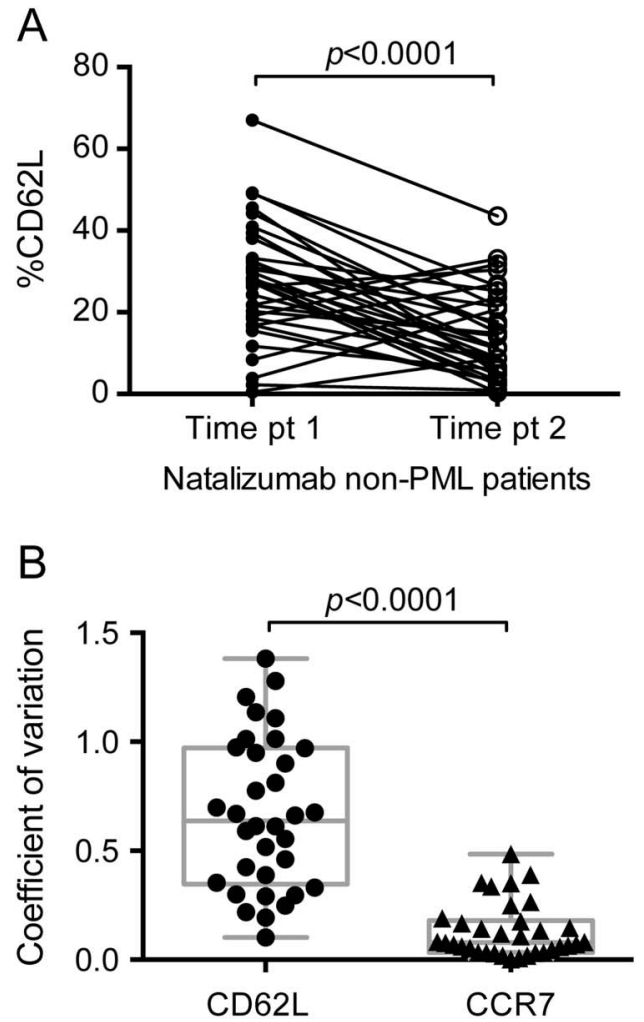

STRATIFY-2

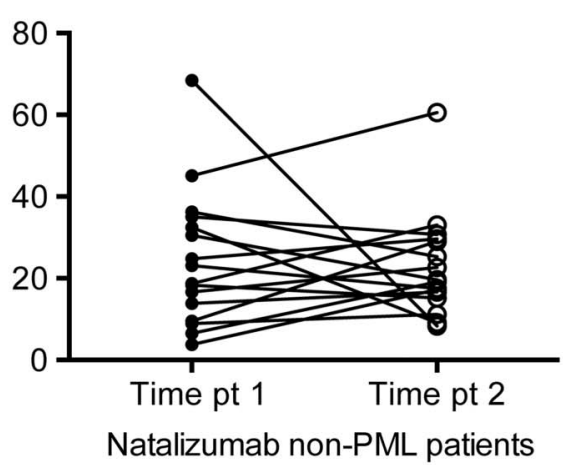

(A) Repeated measurements of \%CD62L at 2 time points at least 6 months apart. (B) Coefficient of variation of \%CD62L and \%CCR7 (on $\mathrm{CD}^{+}{ }^{+} \mathrm{CD} 4{ }^{+} \mathrm{T}$ cells) between samples from the same patients at 2 time points. PML = progressive multifocal leukoencephalopathy. 
both cohorts, we calculated the coefficient of variation $(\mathrm{CV})$ between time points for \%CD62L and the surface receptor \%CCR7 that was measured simultaneously on the same cells. The mean CV of \%CD62L in STRATA and STRATIFY-2 was 0.67 and 0.4 , respectively. In contrast, the mean $\mathrm{CV}$ for \%CCR7 varied little, with STRATA equal to 0.13 and STRATIFY-2 equal to 0.17 (figure 1B). The difference between the CVs for \%CD62L and \%CCR7 is statistically significant in both the STRATA and STRATIFY-2 cohorts, signifying that $\% \mathrm{CD} 62 \mathrm{~L}$ is not a stable outcome measure.

Surface expression of CD62L correlates to lymphocyte viability. A previous study reported that $\% \mathrm{CD} 62 \mathrm{~L}$ decreases in natalizumab-treated patients who later develop PML. ${ }^{3}$ We retrospectively assessed $\% \mathrm{CD} 62 \mathrm{~L}$ on cryopreserved samples from 134 patients from 3 clinical trials. Because CD62L is labile to freeze-thaw, ${ }^{6,7}$ and freezing cells can result in decreased viability of the recovered cells, we hypothesized lymphocyte viability may affect surface expression of CD62L. We assessed the relationship between lymphocyte viability and \%CD62L on cryopreserved $\mathrm{CD}^{+} \mathrm{CD}^{+} \mathrm{T}$ cells and found a positive correlation in both cohorts suggesting sample quality dictates, in part, the results of this assay (figure 2, A and D).

As $75 \%$ viability is considered acceptable for lymphocyte assays on cryopreserved cells ${ }^{6}$ and empirically the ratio of \%CD62L to \%CCR7 decreased proportionally with lymphocyte viability below $75 \%$ (data not shown), we used this threshold for quality control. Median \%CD62L was 26.3 for cells greater than or equal to $75 \%$ viable and 9.8 on samples with less than $75 \%$ lymphocyte viability in the STRATA cohort (figure $2 \mathrm{~B}$ ) and $30.1 \%$ and $11.5 \%$, respectively, in the STRATIFY-2 cohort (figure 2E), indicating that \%CD62L mainly reflects lymphocyte viability after cryopreservation and thawing.

\%CD62L failed to predict progression to PML. We addressed whether \%CD62L indicated altered risk before PML diagnosis. Patient samples were classified as pre-PML when collected at least 6 months before PML diagnosis. \%CD62L did not discriminate significantly between non-PML and active PML (06 months prior to diagnosis) in either STRATA or

Figure 2 Lymphocyte viability confounds \%CD62L levels

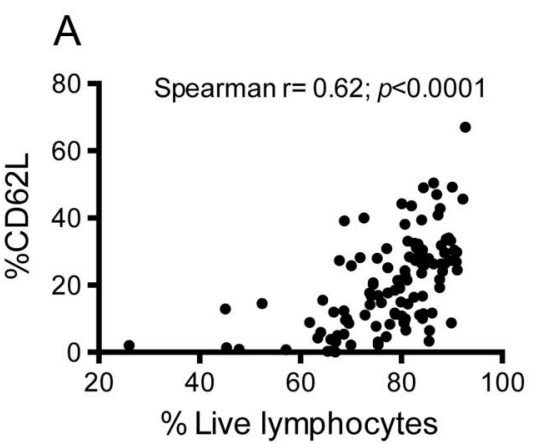

D

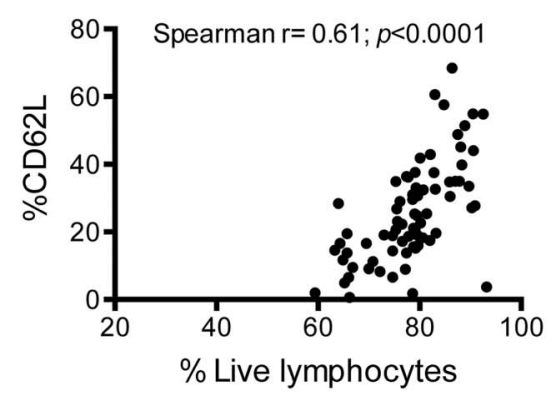

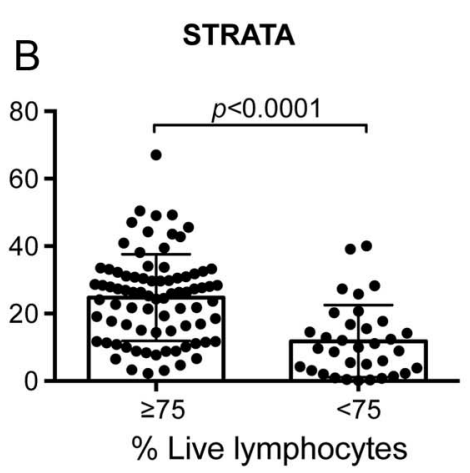

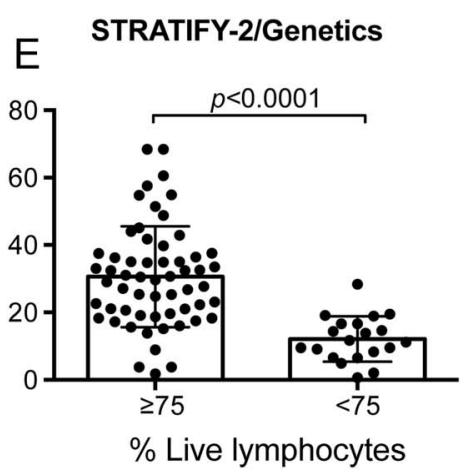

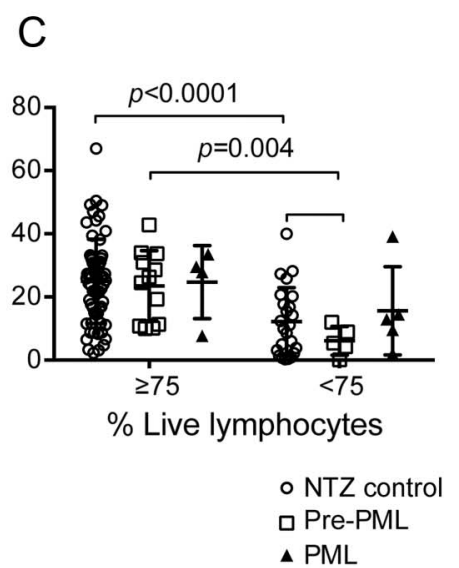

$\mathrm{F}$

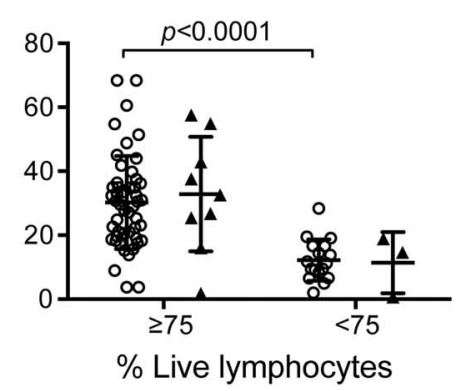

(A) Correlation was assessed between lymphocyte viability and \%CD62L for the STRATA cohort. (B) \%CD62L is shown for all samples from the STRATA cohort, which were divided into 2 groups based on lymphocyte viability. (C) The STRATA data were broken down by disease state and grouped by lymphocyte viability. (D) Correlation was assessed between lymphocyte viability and \%CD62L for the STRATIFY-2/Genetics cohort. (E) \%CD62L is shown for all samples from the STRATIFY-2/Genetics cohort, which were divided into 2 groups based on lymphocyte viability. (F) The STRATIFY-2/Genetics data were broken down by disease state and grouped by lymphocyte viability. NTZ = natalizumab; PML = progressive multifocal leukoencephalopathy. 
STRATIFY-2/Genetics (figure 2, C and F). We observed no difference between median \%CD62L in non-PML (25.9\%) and pre-PML (25.4\%) in the STRATA cohort with lymphocyte viability greater than $75 \%(p=0.73)$ (figure 2C). In contrast, \% CD62L was much lower in natalizumab-treated non-PML samples with viability less than $75 \%$ than in natalizumab-treated non-PML samples with viability greater than $75 \%$ (25.9\% vs $10.55 \%$, $p<$ $0.0001)$. In samples with lymphocyte viability less than $75 \%$, median $\%$ CD62L on pre-PML samples $(5.41 \%)$ was not significantly lower than that of natalizumab-treated non-PML samples (10.55) ( $p>0.05$, figure 2C). Importantly, no difference in lymphocyte viability was observed in comparing non-PML and pre-PML samples from STRATA. Samples collected at PML diagnosis frequently had low viability (figure e-3). Therefore, \%CD62L did not accurately discriminate between STRATA patients who went on to develop PML and those who did not.

\%CD62L did not predict risk of PML in a case-control analysis. We further evaluated \%CD62L in the STRATA dataset longitudinally on the pre-PML/ PML samples (figure 3). Each PML case (filled circles) was matched for age, sex, and number of infusions with samples from 3 to 5 natalizumabtreated patients with MS who did not develop PML (open circles). Nine patients with PML had multiple samples collected in the 6-48 months before diagnosis (pre-PML, black filled circle). Of these 9 patients with PML with multiple pre-PML samples, 7 also had a sample collected 0-6 months prior to PML diagnosis (PML, red filled circle). For 5 of 9 patients with PML, the pre-PML and PML samples fell within the range of the controls. Four of 9 patients with PML had a single sample in which the \%CD62L

Figure $3 \%$ CD62L is not a reliable biomarker for progressive multifocal leukoencephalopathy (PML) risk stratification
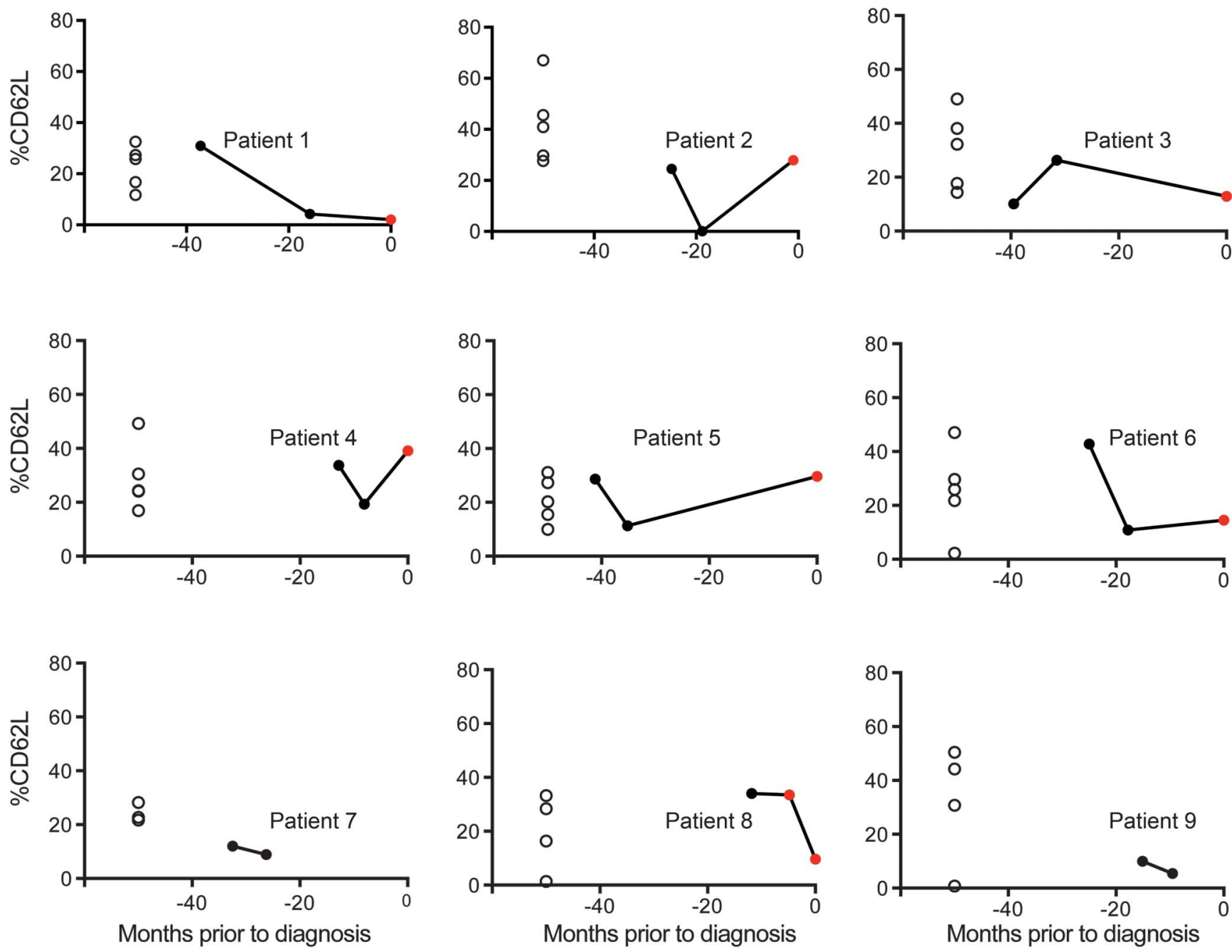

For each patient in the STRATA cohort who developed PML, matched control samples were also stained for \%CD62L. Patients with PML at diagnosis (red circles) and their preceding pre-PML longitudinal time points (black circles) are plotted along with matched controls (open circles) on individual plots. 
fell below the lowest value of their matched controls. However, it was not possible to determine a predictive threshold for \%CD62L below which PML was likely to occur due to the variability of $\% \mathrm{CD} 62 \mathrm{~L}$ in the non-PML group. Therefore, in this retrospective study, \%CD62L could not predict an individual's risk for PML.

\%CD62L fluctuates in various disease states. As part of our evaluation of \%CD62L as a marker of PML risk, we examined changes in $\% \mathrm{CD} 62 \mathrm{~L}$ in various other disease states. We measured \%CD62L on cryopreserved PBMCs of healthy donors before and 7 days and 28 days post influenza vaccination. Three of 11 healthy controls showed a substantial decrease in $\%$ CD62L 28 days after vaccination (figure 4A). $\%$ CD62L in patients hospitalized for total knee replacement surgery or MRSA infection was significantly reduced to $30.9 \%$ and $28.6 \%$, respectively, from $65.2 \%$ in healthy controls (figure 4B). Therefore, a drop in $\%$ CD62L can occur in varied contexts likely to arise in the course of care of patients with MS. As was found in the MS studies, the \%CD62L in this sample collection also correlated with lymphocyte viability (data not shown).

DISCUSSION A preliminary study reported that $\%$ CD62L may improve stratification of patients taking natalizumab who are at risk for developing PML. ${ }^{3}$ This offered an attractive, though complex, assay to give the prescribers of natalizumab additional information regarding the benefit-risk profile and potentially enable wider safe use of natalizumab in anti-JCV antibody-positive patients. However, we found that $\% \mathrm{CD} 62 \mathrm{~L}$ was not a predictive biomarker in a casecontrol retrospective study. Most PBMCs from patients with PML in our study did not have low
$\%$ CD62L prior to or at diagnosis. It can be argued that our study was limited by sample number or monitoring frequency. However, even accepting this possibility, the variation of $\% \mathrm{CD} 62 \mathrm{~L}$ in the natalizumab-treated patients without PML renders the use of this determination impractical in routine clinical care. Underlining this point, we observed a lack of separation between patients with and without PML such that no statistical threshold of \%CD62L for PML risk identification could be established.

Given that many factors have been reported to cause CD62L shedding, including bed rest, ${ }^{8}$ cryopreservation, ${ }^{6}$ and nonsteroidal anti-inflammatory drug use, ${ }^{9}$ we tested the specificity of reduced $\%$ CD62L for potential intercurrent illness. We showed that routine immunization, knee replacement surgery, and bacterial infection also resulted in reduced \%CD62L, further compromising its utility as a PML risk biomarker.

Our findings reported here differ from the results reported previously, likely because sample collection and processing affect CD62L levels. Samples reported previously were collected from 8 sites in Europe and 1 in the United States and were processed in individual academic laboratories. Consistent with this hypothesis, all the low \%CD62L samples in this prior study were transferred to Muenster (Schwab et al., ${ }^{3}$ figure e-1E). In contrast, the pre-PML samples in the present study were collected identically to the controls in the setting of a clinical trial. We also matched cases and controls for age, sex, number of natalizumab infusions, and, where possible, clinic location. It is unlikely that samples described in the prior report could be as well-matched.

One potential limitation of the comparison between the present study and that reported previously lies in technical differences between the assay used here and

Figure $4 \quad \% C D 62 L$ decreases in other disease states

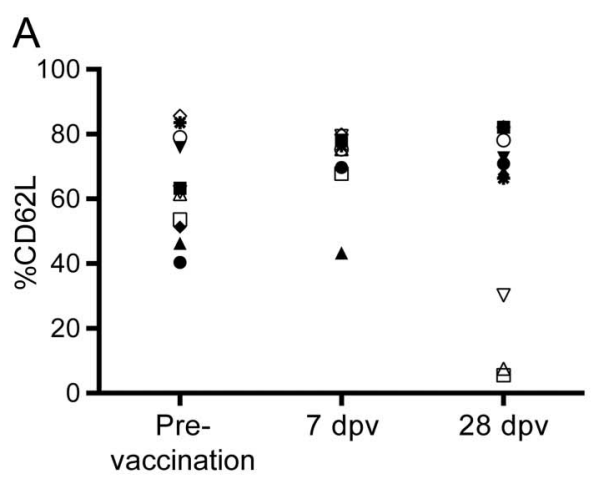

Donor
$\bullet \quad 1$
- 2
× 3
> 4
- 5
$\circ 6$
$\square 7$
$\triangle 8$
$\nabla 9$
$\diamond 10$
$* 11$

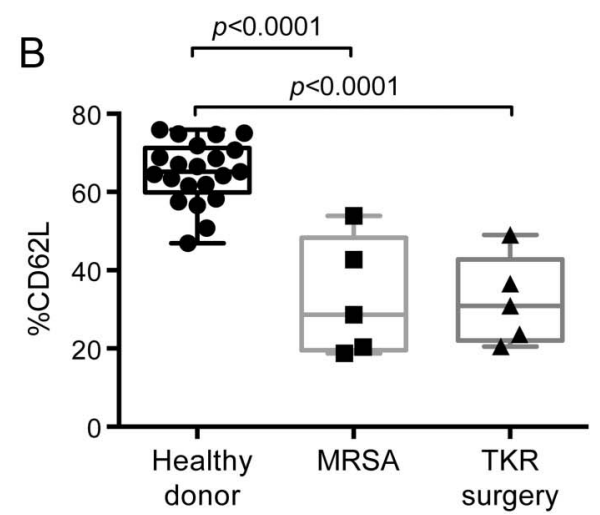

\%CD62L was evaluated in PBMC samples collected from (A) healthy donors pre and 7-28 days post influenza vaccination (dpv) and (B) patients hospitalized due to methicillin-resistant Staphylococcus aureus (MRSA) or total knee replacement surgery (TKR surgery). 
that employed for the prior report. The changes introduced in our assay were designed to enhance reproducibility and potentially enable the deployment of $\% \mathrm{CD} 62 \mathrm{~L}$ as a biomarker for PML in a global setting (figure e-4). We compared each variation in our assay with that used in Muenster (table e-1) and showed directly that no change in the \%CD62L value resulted.

The strong correlation of lymphocyte viability with \%CD62L on the live cell population and the observation that a freeze/thaw cycle is necessary to reveal a low \%CD62L (Schwab et al., ${ }^{3}$ figure e-1A) implies that cells that die in the course of thawing cells cause reduced CD62L on the remaining live cell population. Indeed, we find that mixing thawed cells with low lymphocyte viability with unfrozen cells causes reduced CD62L of the unfrozen cells (data not shown).

Due to the poor performance characteristics for the measurement of \%CD62L in our present studies, one is confronted with safety concerns regarding the use of \%CD62L for stratification of patient risk. A false-negative reading (high \%CD62L) will provide a deceptive sense of security in patients and caregivers, potentially reducing vigilance for PML signs, the early appreciation of which constitute the major determinant of outcome. ${ }^{10}$ Conversely, a false-positive result (of low \%CD62L) will cause patients distress if they continue to use natalizumab and risk increased MS disease activity if they choose to stop treatment. For these reasons, \%CD62L does not meet the rigorous standards required of a clinical biomarker.

\section{AUTHOR CONTRIBUTIONS}

L.A.L. analyzed raw data and composed the manuscript. W.Z. performed all flow cytometry assays and contributed to data analysis. C.S. organized and provided clinical samples for the assays, provided clinical information of participants, and contributed to data analysis. W.W. performed statistical analyses. K.L.O. contributed to experimental design and data analysis. C.L. contributed to data analysis. T.P. coordinated clinical samples and contributed to data analysis. L.G. contributed to experimental design and data analysis. R.M.R. contributed to data analysis and article preparation. E.C.-M. contributed to experimental design and data analysis and article preparation.

\section{ACKNOWLEDGMENT}

The authors thank Margot Brickelmaier for technical help and Sarah Gheuens, MD, PhD, Shibeshih Belachew, MD, PhD, Dominic Paes, $\mathrm{PhD}$, Geoffrey Kuesters, PhD, Shauna Andersson, MD, PhD, Meena Subramanyam, PhD, and Damian Gasparotto, PharmD, for discussions on the clinical impact of these data.

\section{STUDY FUNDING}

This study was supported by Biogen.

\section{DISCLOSURE}

L. Lieberman is an employee of Biogen, Inc., and holds stock. W. Zeng is an employee of Biogen, Inc., and holds stock. C. Singh is an employee of Biogen, Inc., and holds stock. W. Wang is an employee of Biogen, Inc., and holds stock. K. Otipoby is an employee of Biogen, Inc., and holds stock. C. Loh is an employee of Biogen, Inc., and holds stock. T. Plavina is an employee of Biogen, Inc., and holds stock. L. Gorelik is an employee of Biogen, Inc., and holds stock. R. Ransohoff is an employee of Biogen, Inc., and holds stock. E. Cahir-McFarland is an employee of Biogen, Inc., and holds stock. Go to Neurology.org for full disclosures.

Received April 16, 2015. Accepted in final form September 30, 2015.

\section{REFERENCES}

1. Yaldizli O, Putzki N. Natalizumab in the treatment of multiple sclerosis. Ther Adv Neurol Disord 2009;2: 115-128.

2. Bloomgren G, Richman S, Hotermans C, et al. Risk of natalizumab-associated progressive multifocal leukoencephalopathy. N Engl J Med 2012;366:1870-1880.

3. Schwab N, Schneider-Hohendorf T, Posevitz V, et al. Lselectin is a possible biomarker for individual PML risk in natalizumab-treated MS patients. Neurology 2013;81: 865-871.

4. O'Connor P, Goodman A, Kappos L, et al. Long-term safety and effectiveness of natalizumab redosing and treatment in the STRATA MS Study. Neurology 2014;83:78-86.

5. Kister I, Kuesters G, Chamot E, et al. IV immunoglobulin confounds JC virus antibody serostatus determination. Neurol Neuroimmunol Neuroinflamm 2014;1:e29.

6. Weinberg A, Song LY, Wilkening C, et al. Optimization and limitations of use of cryopreserved peripheral blood mononuclear cells for functional and phenotypic T-cell characterization. Clin Vaccine Immunol 2009; 16:1176-1186.

7. Feuerecker M, Kaufmann I, Salam AP, Chouker A. Effects of cryopreservation with polyethylene glycol on the expression of CD11b and CD62L on the surface of polymorphonuclear leukocytes. Cryo Letters 2012;33:151-160.

8. Feuerecker M, Feuerecker B, Matzel S, et al. Five days of head-down-tilt bed rest induces noninflammatory shedding of L-selectin. J Appl Physiol 2013;115:235-242.

9. Herrera-Garcia A, Dominguez-Luis M, Arce-Franco M, et al. In vivo modulation of the inflammatory response by nonsteroidal antiinflammatory drug-related compounds that trigger L-selectin shedding. Eur J Immunol 2013;43: 55-64.

10. Dong-Si T, Richman S, Wattjes MP, et al. Outcome and survival of asymptomatic PML in natalizumab-treated MS patients. Ann Clin Transl Neurol 2014;1:755-764. 


\section{Neurology}

\section{CD62 $\mathrm{L}$ is not a reliable biomarker for predicting PML risk in natalizumab-treated R-MS patients \\ Linda A. Lieberman, Wanyong Zeng, Carol Singh, et al.}

Neurology 2016;86;375-381 Published Online before print December 30, 2015

DOI 10.1212/WNL.0000000000002314

\section{This information is current as of December 30, 2015}

\section{Updated Information \& Services \\ Supplementary Material \\ References \\ Citations \\ Subspecialty Collections}

Errata

Permissions \& Licensing

Reprints including high resolution figures, can be found at: http://n.neurology.org/content/86/4/375.full

Supplementary material can be found at: http://n.neurology.org/content/suppl/2015/12/30/WNL.0000000000002 314.DC1

This article cites 9 articles, 3 of which you can access for free at: http://n.neurology.org/content/86/4/375.full\#ref-list-1

This article has been cited by 5 HighWire-hosted articles: http://n.neurology.org/content/86/4/375.full\#\#otherarticles

This article, along with others on similar topics, appears in the following collection(s):

Multiple sclerosis

http://n.neurology.org/cgi/collection/multiple_sclerosis

Viral infections

http://n.neurology.org/cgi/collection/viral_infections

An erratum has been published regarding this article. Please see next page or:

/content/87/9/960.full.pdf

Information about reproducing this article in parts (figures,tables) or in its entirety can be found online at:

http://www.neurology.org/about/about_the_journal\#permissions

Information about ordering reprints can be found online:

http://n.neurology.org/subscribers/advertise

Neurology ${ }^{\circledR}$ is the official journal of the American Academy of Neurology. Published continuously since 1951 , it is now a weekly with 48 issues per year. Copyright @ 2015 American Academy of Neurology. All rights reserved. Print ISSN: 0028-3878. Online ISSN: 1526-632X.

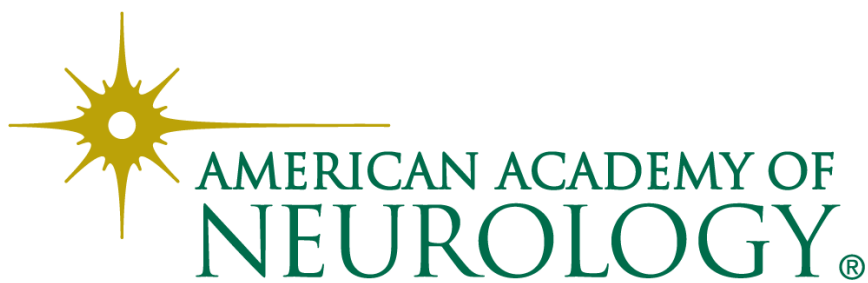




\section{CORRECTION}

CD62L is not a reliable biomarker for predicting PML risk in natalizumab-treated R-MS patients

In the article "CD62L is not a reliable biomarker for predicting PML risk in natalizumab-treated R-MS patients" by L.A. Lieberman et al., ${ }^{1}$ there are errors in table 1 and figure 3 . In table 1, the number of samples reported missed the inclusion of an additional 51 longitudinal NTZ control samples (34 STRATA and 17 non-STRATA) from a serial collection. In figure 3, there is a discrepancy in the assignment of the "at diagnosis" PML samples (red circles). All calculations were performed on the correct data, so neither of these errors affects the conclusions of the manuscript. Corrected versions of both are below. The authors regret the error.

\section{REFERENCE}

1. Lieberman LA, Zeng W, Singh C, et al. CD62L is not a reliable biomarker for predicting PML risk in natalizumabtreated R-MS patients. Neurology 2016;86:375-381.

\begin{tabular}{|c|c|c|c|c|c|c|c|c|c|c|}
\hline \multirow[t]{3}{*}{ Table 1} & \multicolumn{10}{|c|}{ Patient demographics } \\
\hline & \multicolumn{3}{|l|}{ All samples } & \multicolumn{4}{|l|}{ STRATA } & \multicolumn{3}{|l|}{ Non-STRATA } \\
\hline & NTZ ctrl & Pre-PML & PML & NTZ ctrl & $\begin{array}{l}\text { Pre-PML, } \\
\text { no at Dx }\end{array}$ & $\begin{array}{l}\text { Pre-PML + } \\
\text { PML at Dx }\end{array}$ & $\begin{array}{l}\text { PML at Dx } \\
\text { only }\end{array}$ & NTZ ctrl & Pre-PML & PML \\
\hline No. of patients & 104 & 9 & $21^{a}$ & 55 & 2 & 7 & 1 & 49 & 0 & 11 \\
\hline $\begin{array}{l}\text { No. of samples } \\
\text { (patients) }\end{array}$ & 155 & 17 & 21 & 89 & $17\left(9^{\mathrm{a}}\right)$ & $9\left(8^{b}\right)$ & & 66 & 0 & 12 \\
\hline \multicolumn{11}{|l|}{ Age, y } \\
\hline Mean \pm SD & $44.6 \pm 7.96$ & $42 \pm 5.65$ & $44.6 \pm 7.32$ & $42.4 \pm 7.66$ & $42 \pm 5.65$ & $42.4 \pm$ & 7.77 & $47.1 \pm 7.62$ & NA & $46 \pm 7.39$ \\
\hline \multicolumn{11}{|l|}{ Sex } \\
\hline$\%$ Female & 77.9 & 66.7 & 84.2 & 78.2 & 66.7 & 75 & & 77.6 & NA & 90.1 \\
\hline \multicolumn{11}{|l|}{ No. of NTZ doses } \\
\hline Mean \pm SD & $63 \pm 17.13$ & $52 \pm 5.57$ & $64 \pm 13.89$ & $50 \pm 8.41$ & $52 \pm 5.57$ & $70 \pm 1$ & 5.74 & $77 \pm 13.25$ & NA & $59 \pm 10.59$ \\
\hline
\end{tabular}

Abbreviations: $\mathrm{NA}=$ not available; $\mathrm{NTZ}=$ natalizumab; $\mathrm{PML}=$ progressive multifocal leukoencephalopathy.

${ }^{a}$ We do not have at diagnosis samples for 2 of these patients.

${ }^{b}$ One patient with PML has 2 samples within 1 month of diagnosis.

Figure 3
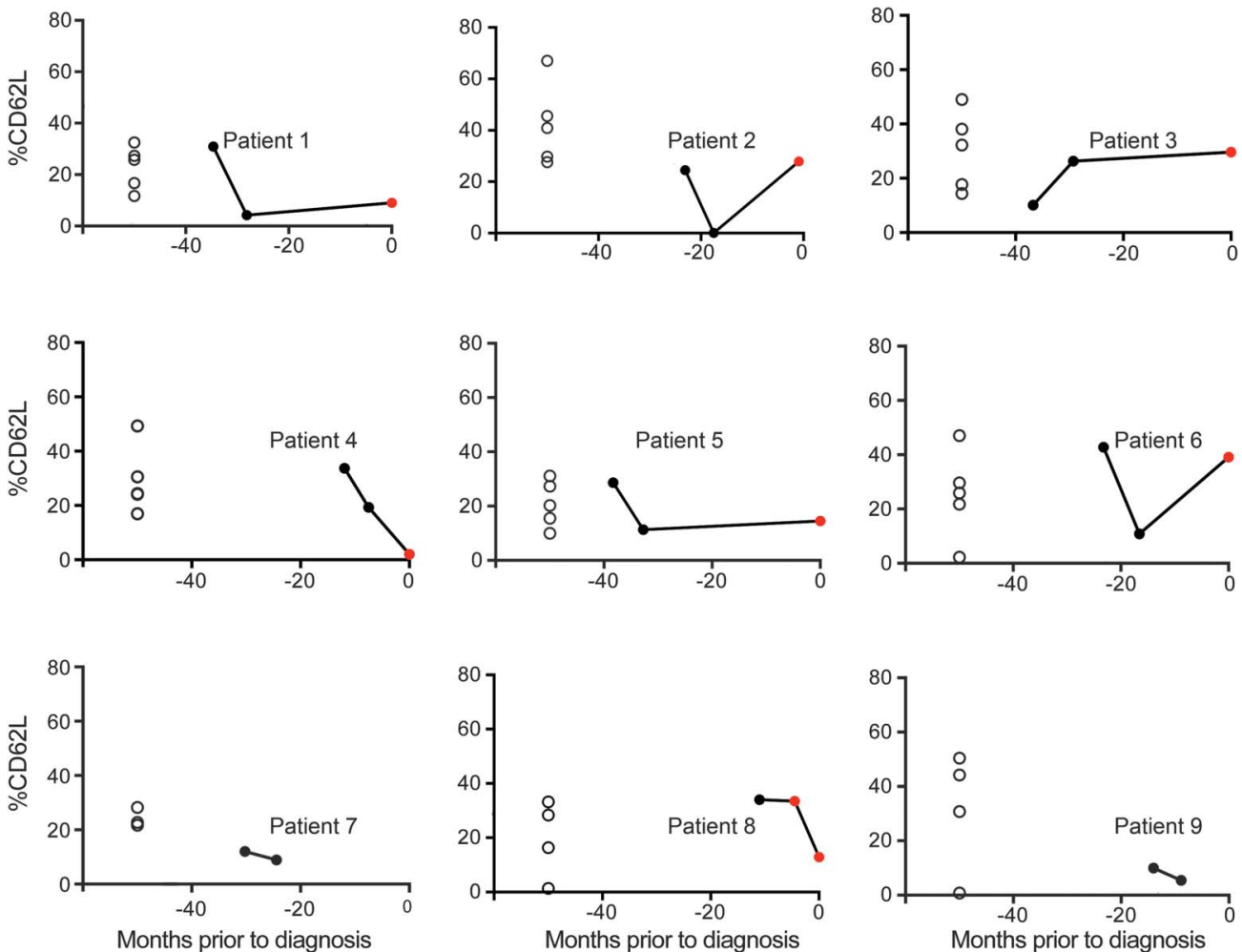